\title{
Erratum to: The Neural Stem Cell Fate Determinant TLX Promotes Tumorigenesis and Genesis of Cells Resembling Glioma Stem Cells
}

\author{
Hyo-Jung Park, Jun-Kyum Kim, Hye-Min Jeon, Se-Yeong Oh, Sung-Hak Kim, Do-Hyun Nam', and \\ Hyunggee Kim*
}

\section{Erratum to: Mol. Cells 30, 403-408 (2010)}

DOI/10.1007/s10059-010-0122-z

This paper was initially submitted to Journal 'Molecules and Cells' without approval from two coauthors. According to the decision of editorial committee, I, as a corresponding author for this paper, withdraw authorship of two coauthors who did not agree to use of $\mathrm{XO} 1, \mathrm{XO} 2$, and $\mathrm{XO} 3$ cells shown in Fig. 1B. Thus, we change data shown in Fig. $1 \mathrm{~B}$ by removing expression of TLX in these cells. We deeply regret this circumstance and apologize to the community.

Fig. 1B

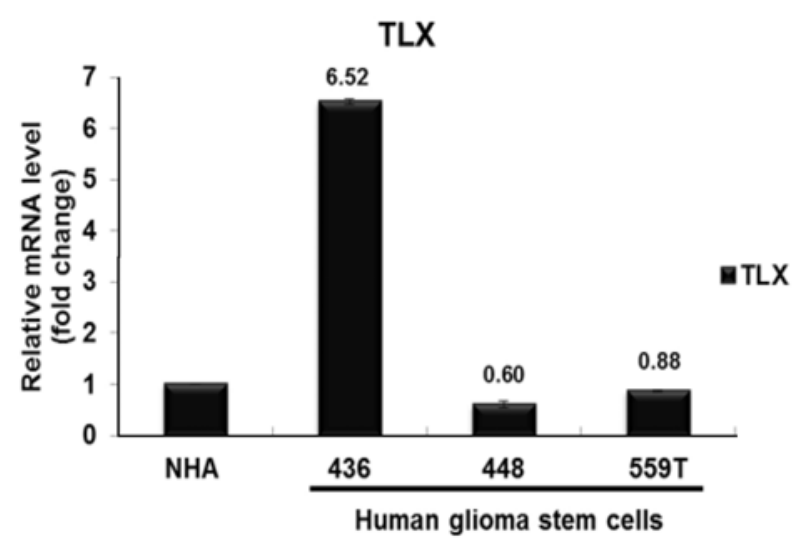

The online version of the original article can be found under $\mathrm{DOI} / 10.1007 / \mathrm{s} 10059-010-0122-\mathrm{z}$.

Cell Growth Regulation Laboratory, School of Life Sciences and Biotechnology, Korea University, Seoul 136-713, Korea, ${ }^{1}$ Department of Neurosurgery, Samsung Medical Center and Samsung Biomedical Research Institute, Sungkyunkwan University School of Medicine, Seoul 135-710, Korea ${ }^{*}$ Correspondence: hg-kim @ korea.ac.kr 